244 Tropelías. Revista de Teoría de la Literatura y Literatura Comparada, número extraordinario 2 (2017) Àlex Martín Escribà

\title{
MANUEL DE PEDROLO, BARCELONA Y SANGRE A BAJO PRECIO (1954): ESCRIBIR NOVELA NEGRA EN ESPAÑA DURANTE LA DICTADURA
}

\author{
Àlex MARTÍN ESCRIBÀ \\ Universidad de Salamanca \\ martinescriba@usal.es
}

anuel de Pedrolo y la ciudad de Barcelona tienen mucho que ver con el nacimiento de la
novela negra en España. Si nos centramos en el espacio urbano barcelonés hay que
mencionar una serie de referentes históricos y políticos que le permitieron ambientar este tipo de novelas dentro de un tiempo y un espacio muy concreto. La referencia a la ciudad condal en la mayoría de las novelas que se inscriben dentro de esta tradición vino motivada fundamentalmente por la intención de establecer una crónica dentro de un contexto determinado. Y es que el imaginario barcelonés cumple con toda una serie de requisitos indispensables: Barcelona era la ciudad de la revolución industrial, compleja y conflictiva, y contaba ya con un pasado histórico y político relevante.

Es en este punto eventual donde podemos hablar ya de las generaciones de los años cuarenta y cincuenta, precedentes poco considerados y estudiados hasta la actualidad. Desgraciadamente, la nota predominante del franquismo supuso la represión más feroz en cuanto al ejercicio de la censura y de la represión cultural y política. Ahora bien, la sociedad y los artistas y literatos no se quedaron de brazos cruzados. Mientras algunos escritores recogían la herencia de la preguerra, otros comenzaban a plantearse caminos abiertos como la literatura del absurdo, el realismo o existencialismo. Hubo ya algunos intentos de adaptar el canon norteamericano del género negro. El primer autor que refleja todos estos condicionantes de carácter realista a mediados de la década de los cincuenta fue Mario Lacruz con El Inocente (1953), una novela experimentalista sobre la huida de un personaje de nombre Virgilio Delise que escapa del cuerpo policial en busca de su inocencia. Se trata de una fuga no sólo de una falsa acusación, sino también una búsqueda de la libertad dentro de un régimen totalitario.

También destacó Tomás Salvador que con Los atracadores (1955), El atentado (1960) y El charco (1969) escribió con tres novelas toda una crítica implícita al sistema de valores que imperaba en la sociedad dictatorial de aquellos años. También debe mencionarse -en catalán- a Rafael Tasis i Marca, que fue el primer autor que escribió - con vocación de saga- una trilogía del género. El escritor afirmaba que «Barcelona necesitaba una escuadra de novelistas que se enamoren de su evolución, de 
su grandeza pero también de sus miserias» (1935: 123). Fruto de ello nació su trilogía, formada por los títulos La Bíblia valenciana (1955), És hora de plegar (1956) y Un crim al paralelo (1960).

Por su parte, y también en catalán, uno de los autores fundamentales y que ocupará este artículo es Manuel de Pedrolo. Considerado como uno de los padres fundadores del género negro en España, fue definido por Andreu Martín como «el primer escritor profesional» (1988: 6):

[Fue] el primer autor de género que me hizo comprender que era posible ambientar una novela policíaca en las calles de Barcelona, con detectives viajando en Seiscientos y teniendo dificultades para aparcar. Estos detalles, que pueden parecer ridículos, eran fundamentales a la hora de escribir aquí policíaco con su principal e imprescindible característica: la verosimilitud.

La década de los sesenta, cuando el escritor leridano escribe buena parte de sus novelas, coincide con una época de cierto renacimiento de las editoriales en la ciudad condal y de la creación de un nuevo mercado literario. De esta manera se intentaba abrir al mercado nuevos horizontes narrativos en Cataluña, como ocurrió con la colección «La Cua de Palla» (1963-1971) dirigida por Pedrolo, que intentó atraer la lectura del género a miles de lectores. Efectivamente, en 1963, Edicions 62 empezó a editar una compilación de novelas criminales que recogieron las obras más representativas del género policíaco y negro. En esta colección se tradujeron los clásicos hard-boiled estadounidenses y algunos franceses que hasta entonces la mayoría de lectores solo habían podido leer en versión original. Entre los norteamericanos cabe destacar a Dashiell Hammett, Ross Macdonald, James M.Cain, Mickey Spillane, Raymond Chandler, etc.; entre los franceses, Sébastien Japrisot, Pierre Véry o Georges Simenon. El gusto de Pedrolo por todos estos autores mostró un interés en su narrativa por las experiencias humanas y por reflejar al hombre de su tiempo, ya que el escritor vio en la novela negra norteamericana -sobre todo la vertiente crook story y particularmente las novelas de William Riley Burnett y, sobre todo, de James M. Cain- una salida perfecta para sus novelas. Las situaciones complejas, la moralidad y la opresión social fueron algunos de sus temas predilectos, así como la utilización de un lenguaje duro, las escenas violentas y la precipitación de los hechos narrados fueron algunas de sus características dentro de su obra negra y policíaca. Por ello algunos de sus títulos, traducidos como Sangre a bajo precio (1954), El inspector llega tarde (1960) y Juego sucio (1965), están narrados desde el punto de vista del malhechor, mientras que tan solo en una ocasión Morderse la cola (1968), Pedrolo dibujó el arquetipo del detective norteamericano. Con sus narraciones, el escritor incorporaba la llamada novela negra a nuestra literatura, tendencia que luego continuarán un número ingente de escritores en la actualidad.

Sangre a bajo precio -originalmente Es vessa una sang fácil-fue catalogada de experimental y definida por su autor como una «narración tough», donde destacaba que, «me atrajo la posibilidad de introducir un tejido policíaco, [...] pero que explicara a los personajes en términos al fin y al cabo psicológicos» (Coca, 1991: 42). A pesar de su difícil adscripción al género negro, dicha novela contiene una gran dosis de originalidad y un rechazo de los tópicos detectivescos, puesto que si por un lado muestra influencias de William Faulkner en el estilo y en la forma de escribir, por otro no puede negar su similitud argumental con la novela The Asphalt Jungle (1949) de William Riley Burnett: 
En la narración de aquel atraco y de la fuga de los ladrones, con la traición de uno y el choque que debe eliminarlo junto con su perseguidor, estaba el realismo implacable de las mejores tough novels americanas, la lección de Faulkner, la objetividad impasible de un narrador que describe hechos y conversaciones sin entrar en el espíritu de sus personajes -0 , por lo menos, dejando que este espíritu se manifieste gracias al monólogo interior- (Tasis 1957: 12).

En efecto, Pedrolo parte de la base como núcleo argumental de una sublínea del género negro, concretamente la crook story, dentro de las denominadas hold-ups, un tipo de novela que se caracterizaba, en palabras de Javier Coma, por una «corriente que desplaza el protagonismo del detective al del delincuente profesional y obtiene inmediatamente un apoyo espontáneo en la cinematografía de la época» (1985: 48).

Sangre a bajo precio es, por lo tanto, una novela de delincuencia común, de traiciones y venganzas, de asesinatos, robos y palizas donde unos delincuentes comunes, algunos de onomástica extravagante-Nero, Blasi, Juan, Trencat y What-deciden atracar una sucursal bancaria para conseguir una buena fortuna. Tras la facilidad y el éxito de la operación -en la que se consiguen embolsarse cerca de un millón y medio de pesetas-, deciden escapar cada uno por su cuenta con tal de no levantar sospechas y reunirse unas horas después en un apartamento situado en el barrio popular del Putxet, en la ciudad de Barcelona. La sorpresa se produce cuando todos se presentan menos Juan, que es precisamente el encargado de llevar el dinero. Tras una agónica espera en la casa, todos los personajes empiezan a impacientarse y a extraer conclusiones de todo tipo, desde sospechas de toda índole del acusado como la fuga con el dinero hasta la complicidad con la policía, que conllevan una tensión narrativa en un recinto cerrado - un apartamento- que provoca fuertes discusiones y un aumento de tensión y violencia a medida que avanza la acción. A partir de allí empieza un ajuste de cuentas y cruento entre los atracadores. De hecho, para tensar más si cabe la acción Pedrolo presenta una narración ininterrumpida, sin indicadores de capítulos ni partes que la dividan, ausencia que viene dada por la intención de enfatizar -todavía más- las acciones de la novela.

Ambientada en la Barcelona de la posguerra, la narración retrata con toda fidelidad el contexto social del momento. Como afirma Andreu Martín la «Barcelona del final del racionamiento y el pan negro, cuando un cóctel con guinda costaba cincuenta céntimos y viajar en tranvía costaba quince» (1988: 7). Nos encontramos, pues, ante un reflejo de una ciudad compleja ya que es la Barcelona de los fusilamientos de los anarquistas, huelgas, persecuciones, represiones policiales... De hecho, una de las marcas de identidad del escritor ha sido la de mostrar las desigualdades sociales y los contrastes entre los diferentes barrios barceloneses, reflejando un gran interés por el mundo de la urbe, el lumpen y la sociedad que le rodea. Así aparecen de forma regularizada los medios de transporte -redes ferroviarias, automóviles y en gran parte, tranvías-, que es una forma más de mostrar cómo vive la sociedad del momento. Para dar aún más verosimilitud e intensidad al relato, Pedrolo alterna la narración lineal en tercera persona con intervenciones en cursiva de los atracadores a través de monólogos interiores. Este enfoque plural a través de varias voces le sirve al autor para reflejar una violencia explícita y unas persecuciones frenéticas a lo largo de la historia. En este sentido, el crítico Julio Manegat afirmaba que 
Manuel de Pedrolo, Barcelona y Sangre a bajo precio (1954): escribir novela negra...

Pedrolo, partiendo de un hecho sólidamente construido, la abre en abanico para llevarnos al encuentro de las consecuencias de este hecho en cada uno de los protagonistas que lo viven. La técnica de este procedimiento nos recuerda no sólo al gran escritor Simenon, sino también ciertos aspectos de la moderna novelística norteamericana. Existe una línea central segura, estudiada segundo a segundo, y, al margen de ella, provocada por ella, por ella conducida, está la línea personal de cada uno de los que, directa o indirectamente, han intervenido en el hecho motor; el atraco, en Barcelona, a un banco. Hasta aquí es todo absolutamente normal. Luego se ofrece al lector un nuevo interés; uno de los atracadores huye con el dinero robado y los demás se convierten en policías del compañero evadido; los que han de ser perseguidos, persiguen. La novela entonces entra en una acción directa, viva, escrupulosa. Toda la técnica de Pedrolo se vierte en estas páginas (1954: 36).

Sangre a bajo precio es, pues, una narración de acciones rápidas y de ruptura con los moldes preestablecidos. Una novela policíaca original y ejemplar que despertó el interés de Josep $\mathrm{M}^{\mathrm{a}}$ Espinàs y Julio Coll, y que realizaron a partir de la base textual de Pedrolo una adaptación teatral y cinematográfica que muestran no solo el interés que suscitó un texto innovador en el cual los protagonistas ya no eran policías ni fueras del orden sino un grupo de delincuentes, una banda de atracadores que pretendían cometer un golpe:

Nos parece absolutamente meritorio que una novela breve y escrita sin otra pretensión que la de novelar nos dé la seguridad de que en Pedrolo existe un escritor de auténtica categoría. Y nos parece absurdo que tenga que dar la cara al público con esta obra, sugestiva pero no menor, y permanezcan inéditas sus novelas mayores. Sangre a bajo precio parecerá a muchos un relato fácil, irrelevante. Con un poco de atención y honradez crítica, la conclusión se desprende sin esfuerzo: sólo se puede escribir este libro aparentemente sencillo, redondo y expresivamente contenido [...] cuando el autor no es un aficionado sino un novelista con oficio y criterio (Espinàs 1954: 23).

En definitiva, una novela original y un autor pionero que - entre muchos otros méritos-introdujo el género negro en España junto a autores como Mario Lacruz, Rafael Tasis o Tomás Salvador y que sigue inexplicablemente condenado en olvido.

\section{Referencias bibliográficas}

CocA, J. (1991): Pedrolo, perillós?, Converses amb Manuel de Pedrolo. Barcelona, La Magrana. (1959): És perillós fer-se esperar. Barcelona, Nereida

COMA, J. (1985): Diccionari de la novel-la negra nord-americana. Barcelona, Edicions 62.

Manegat, J. (1954): «Es vessa una sang fácil, por Manuel de Pedrolo», El Noticiero Universal, Barcelona, 22 de junio, p. 36.

Martín, A. (1990): «Detectives con 600», El País, Barcelona, 27 de junio, p. 35.

PEDrolo, M. (1954):Es vessa una sang fácil. Barcelona, Albertí editores. (1988): Sangre a bajo precio. Barcelona, Ediciones B.

TASIS, R. (1957): «L'obra narrativa de Manuel de Pedrolo», Quart Creixent/, 3, pp. 10-17. 